\title{
Role of tin as a reducing agent in iron containing heat absorbing soda-magnesia-lime-silica glass
}

\author{
AMAN and S P SINGH* \\ Department of Ceramic Engineering, Institute of Technology, Banaras Hindu University, Varanasi 221 005, India
}

MS received 7 May 2003; revised 13 September 2004

\begin{abstract}
The role of tin as a reducing agent in a $18 \mathrm{Na}_{2} \mathrm{O} \cdot 2 \mathrm{MgO} \cdot 8 \mathrm{CaO} \cdot 72 \mathrm{SiO}_{2}$ glass containing a definite amount of total, $\Sigma \mathrm{Fe}=\left[\mathrm{Fe}^{2+}\right]+\left[\mathrm{Fe}^{3+}\right]$, was investigated with different concentrations of total tin, $\Sigma \mathrm{Sn}=$ $\left[\mathrm{Sn}^{2+}\right]+\left[\mathrm{Sn}^{4+}\right]$, by absorption spectra of iron ions in the optical range 300-1200 $\mathrm{nm}$ recorded on a JASCO7800 spectrophotometer. The single broad absorption band for $\mathrm{Fe}^{2+}$ ion was marked at $1055 \mathrm{~nm}$ in the near infrared region and a narrow weak band for $\mathrm{Fe}^{3+}$ ion at its $\lambda_{\max }$ at around $380 \mathrm{~nm}$ was observed in the silicate glass. The proportion of ferrous iron was found to increase in the glass in the beginning with the addition of tin up to $0.788 \% \Sigma \mathrm{Sn}$ and then it approached a maxima with $1.182 \% \Sigma \mathrm{Sn}$. Further addition of tin was found to be futile for the constant iron concentration of $0.875 \%$ for achieving higher $\left[\mathrm{Fe}^{2+}\right] /\left[\mathrm{Fe}^{3+}\right]$ ratio for maximum heat absorption due to $\mathrm{Fe}^{2+}$ ion in the glass. The mechanism of the process was discussed on the basis of $\mathrm{Sn}^{2+} / \mathrm{Sn}^{4+}$ and $\mathrm{Fe}^{2+} / \mathrm{Fe}^{3+}$ mutual redox interaction in the molten glass at $1400^{\circ} \mathrm{C}$. The suitable limit of tin was suggested to be $0.788 \leq x \leq 1.182 \%$ by wt for $0.875 \%$ of total iron for getting maximum ferrous ion in the glass.
\end{abstract}

Keywords. Tin reducing agent; iron heat absorption; silicate glass.

\section{Introduction}

Heat-absorbing glasses are generally used for glazing buildings, observation towers, automobile vehicles as well as for making eye-protecting glasses and welder's goggles (Shand 1958). Intensity of heat absorption in such glasses depends on the concentration of ferrous ions, which have a strong absorption band in the near infrared region between 1000 and $1100 \mathrm{~nm}$ (Bamford 1961, 1962). The proportion of iron present in the ferrous state is determined by the $\mathrm{Fe}^{2+}-\mathrm{Fe}^{3+}$ equilibrium which shifts more towards the reduced state with decreasing partial pressure of oxygen, increasing melting temperature and decreasing basicity of glasses (Johnston 1964; Majumdar and Lahiri 1975; Wong and Angell 1976; Russel et al 1988). In order to keep very high proportion of iron in the ferrous state, the heatabsorbing glasses are melted under strongly reducing conditions with suitable reducing agents. The reducing agents, which are mostly carbonaceous materials, react with available oxygen in the glass melt reducing its partial pressure.

The concentration of the reducing agents added to the glass batch decreases with increasing duration of melting and after certain duration of heat treatment time, no reducing agents are left in the glass melt. At that stage, the partial pressure of oxygen in the glass melt becomes much lower than the partial pressure in the furnace atmosphere

\footnotetext{
*Author for correspondence
}

above the melt. After the consumption of all the reducing agents, the partial pressure of oxygen in the glass melt tends to increase and adjust itself to the partial pressure of oxygen in the furnace atmosphere. As a result, the concentration of iron present in the ferrous state decreases. In order to stabilize the proportion of iron present in the ferrous state, there is a need of a redox pair whose lower valence state should have greater affinity for oxygen than the $\mathrm{Fe}^{2+}$ ion. The standard reduction potential of $\mathrm{Sn}^{2+} / \mathrm{Sn}^{4+}$ redox $(0 \cdot 15 \mathrm{eV})$ in comparison to $\mathrm{Fe}^{2+} / \mathrm{Fe}^{3+}$ redox $(0.77 \mathrm{eV})$ clearly indicates that $\mathrm{Sn}^{2+}$ ions have greater affinity for oxygen than $\mathrm{Fe}^{2+}$ ions in aqueous solution (Vogel 1978). Moreover, tin oxide is known to act as a thermo reducing agent in copper and gold ruby glasses (Stookey 1949; Weyl 1951). In view of standard reduction potential of $\mathrm{Sn}^{2+} / \mathrm{Sn}^{4+}$ as well as $\mathrm{Fe}^{2+} / \mathrm{Fe}^{3+}$ redox pairs, Kumar et al (1991) studied the effect of divalent tin on the absorbance maxima due to $\mathrm{Fe}^{2+}$ and $\mathrm{Fe}^{3+}$ ions at different heat treatment times at a constant temperature in a binary sodium-silicate $\left(30 \mathrm{Na}_{2} \mathrm{O} \cdot 70 \mathrm{SiO}_{2}\right)$ glass. They varied the concentration of tin and iron both together as such and the quantitative concentration of tin for addition in sodium silicate glass containing a definite amount of iron could not be ascertained. Most of the commercial heat absorbing glasses are the soda-magnesia-lime silica glasses containing iron. Therefore, in the light of above facts, the present study was undertaken to investigate the effect of varying concentration of tin as a reducing agent for a definite amount of iron concentration present in sodamagnesia-lime silica glass at high temperature. 


\section{Experimental}

For preparing a series of $18 \mathrm{Na}_{2} \mathrm{O} \cdot 2 \mathrm{MgO} \cdot 8 \mathrm{CaO} \cdot 72 \mathrm{SiO}_{2}$ glass batches, acid-washed quartz and analytical reagent grade chemicals were used. Glasses containing the desired tin and iron contents of ultimate glass as $\mathrm{SnO}(0 \cdot 447-$ $1.788 \mathrm{wt} \%)$ and $\mathrm{Fe}_{2} \mathrm{O}_{3}(1.25 \mathrm{wt} \%)$ were melted in a Pt$10 \% \mathrm{Rh}$ crucible of $100 \mathrm{ml}$ capacity kept in an electric globar furnace at $1400^{\circ} \mathrm{C}$. After $12 \mathrm{~h}$ of melting the glasses were poured onto an aluminum sheet, crushed and remelted for another $4 \mathrm{~h}$ to ensure homogeneity. When the rapid quenching of glass melt is done in air atmosphere by pouring it from $1400^{\circ} \mathrm{C}$ to lower temperature it looses its heat to the surroundings very quickly to form glass and the aluminium sheet does not melt during this. During fast cooling of the melt when it is taken out of the furnace the viscosity of the melt increases sharply with decrease in temperature and it attains of the order of around $2.5 \times$ $10^{13}$ and $4.0 \times 10^{14}$ poise at its annealing and strain points, respectively. The phenomena of fast and continuous cooling of the melt with time towards lower temperature in air from $1400^{\circ} \mathrm{C}$ does not unlikely coincide enough to the discontinuous melting of the metallic aluminium sheet in which the temperature is held constant at its melting point within certain intervals of time. In other words, the time-temperature relationship for glass melt is different in nature from that of the metal. So, the melting of aluminium is practically not observed even though the melting point of aluminium metal is far below than the glass melt at $1400^{\circ} \mathrm{C}$. They were taken out of the furnace and poured into a rectangular heated steel mould onto an aluminium plate and annealed at $450^{\circ} \mathrm{C}$ in an annealing furnace for $2 \mathrm{~h}$ and then slowly cooled to room temperature. After grinding and polishing the absorption spectra of glass samples were recorded on a JASCO-7800 recording spectrophotometer (Japan Spectroscopic Company) in the optical range 300-1200 $\mathrm{nm}$. The thickness of these samples were also measured in order to calculate the intensity of the ferrous and ferric bands at their wavelength maxima in the glass, respectively.

\section{Results and discussion}

The results presented in figure 1 show the effect of divalent tin on the optical absorption characteristics of $\mathrm{Fe}^{2+}$ and $\mathrm{Fe}^{3+}$ ions in soda-magnesia-lime-silica glass. The single broad absorption band due to ferrous iron was centred at around $1055 \mathrm{~nm}$ in near infrared region whereas a narrow weak absorption band was centred near the visible region at around $380 \mathrm{~nm}$ in the glass due to ferric ion. In addition to this the other two weak absorption bands are also due to ferric ion which were also centred at $422 \mathrm{~nm}$ and $445 \mathrm{~nm}$ in the visible region as presented in optical absorption spectra of iron in the glass (figure 1). The ratio of ferrous to ferric iron $\left(\mathrm{Fe}^{2+} / \mathrm{Fe}^{3+}\right)$ in the glass containing different concentrations of tin in presence of a definite amount of total iron were calculated using the following Bamford (1977) equation

$$
f /(1-f)=0 \cdot 133\left[\left(A_{1055}-0 \cdot 036\right) /\left(A_{380}-0 \cdot 036\right)\right],
$$

where, $f$ is the fraction of $\mathrm{Fe}^{2+}$ ion in the glass, $1-f$ the fraction of $\mathrm{Fe}^{3+}$ ion in the glass, $A_{1055}$ the absorbance/cm due to $\mathrm{Fe}^{2+}$ ion at $\lambda_{\max }$ at around $1055 \mathrm{~nm}$ and $A_{380}$ the absorbance/cm due to $\mathrm{Fe}^{3+}$ ion at $\lambda_{\max }$ at around $380 \mathrm{~nm}$. The results are presented in table 1 . The $\left[\mathrm{Fe}^{2+}\right] /\left[\mathrm{Fe}^{3+}\right]$ ratio as given in table 1 was found to increase progressively with the increasing concentration of total tin and after a certain limit it became constant with the concentration of tin as shown in figure 2. The variation of the ratio of $\left[\mathrm{Fe}^{3+}\right] /\left[\mathrm{Fe}^{2+}\right]$ with the concentration of tin was obviously found to decrease and became constant with increasing concentration of tin in the glass.

In order to ensure whether the wt $\%$ concentration of total iron as introduced in the glass batch remains the same in the finished glass, it is mentioned herewith that during mutual redox interaction of $\mathrm{Fe}^{2+}-\mathrm{Fe}^{3+}$ and $\mathrm{Mn}^{2+}$ $\mathrm{Mn}^{3+}$ equilibrium in a sodium silicate $\left(30 \mathrm{Na}_{2} \mathrm{O} \cdot 70 \mathrm{SiO}_{2}\right)$ glass, Singh and Kumar (1992) found spectrocolorimetrically that total concentrations of iron and manganese added in the glass remained the same in the melt with change in redox ratio respectively within an experimental error even up to $20 \mathrm{~h}$ of its heat treatment at $1400^{\circ} \mathrm{C}$.

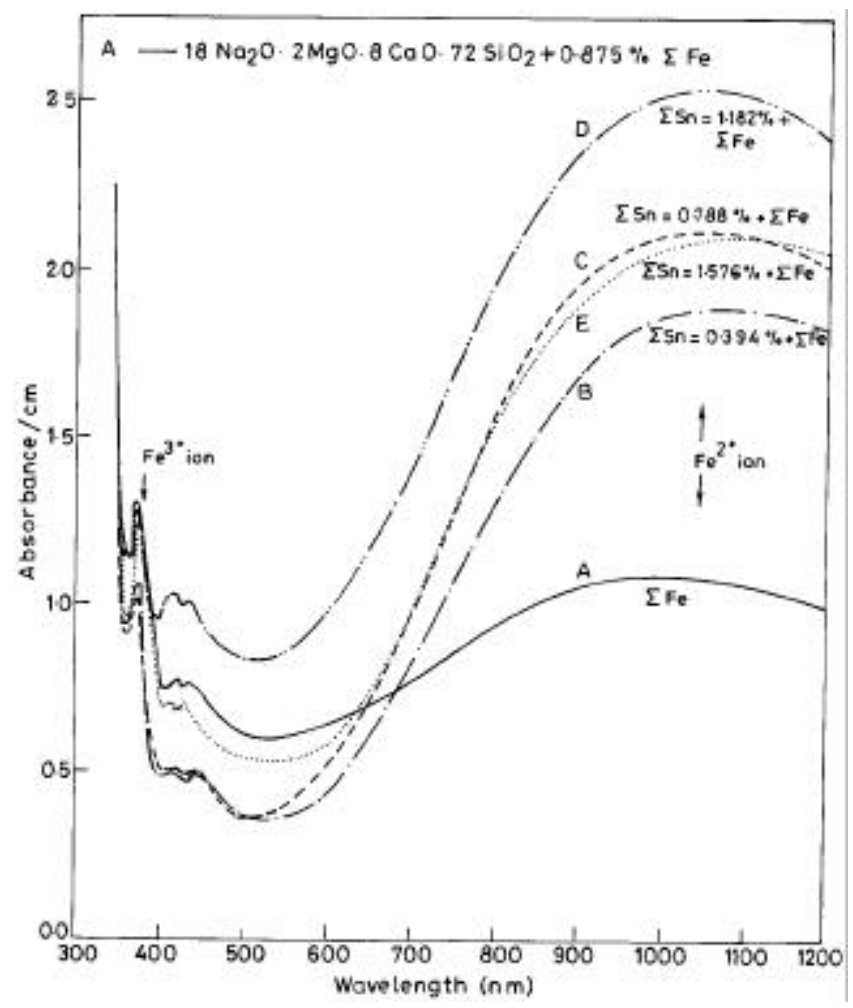

Figure 1. Effect of divalent tin on the optical absorption characteristics of $\mathrm{Fe}^{2+}$ and $\mathrm{Fe}^{3+}$ ions in soda-magnesia-limesilica glass. $\Sigma \mathrm{Fe}=\left[\mathrm{Fe}^{2+}\right]+\left[\mathrm{Fe}^{3+}\right] ; \Sigma \mathrm{Sn}=\left[\mathrm{Sn}^{2+}\right]+\left[\mathrm{Sn}^{4+}\right]$. 
Table 1. Effect of concentration of tin on the proportion of $\mathrm{Fe}^{2+} / \mathrm{Fe}^{3+}$ redox in a soda-magnesia-lime-silica glass containing a definite amount of total iron by weight $\%$ at $1400^{\circ} \mathrm{C}$.

\begin{tabular}{|c|c|c|c|c|c|c|}
\hline \multirow{2}{*}{$\begin{array}{l}\text { Sample } \\
\text { no. }\end{array}$} & \multirow{2}{*}{$\begin{array}{c}\text { Absorbance }\left(\mathrm{Fe}^{2+}\right) \\
\text { at wavelength max } \\
(\sim 1055 \mathrm{~nm}) / \mathrm{cm}\end{array}$} & \multirow{2}{*}{$\begin{array}{l}\text { Absorbance }\left(\mathrm{Fe}^{3+}\right) \\
\text { at wavelength max } \\
(\sim 380 \mathrm{~nm}) / \mathrm{cm}\end{array}$} & \multirow{2}{*}{$\begin{array}{l}\text { Thicknesses } \\
(\mathrm{cm})\end{array}$} & \multicolumn{2}{|c|}{ Concentration (wt.\%) } & \multirow{2}{*}{$\begin{array}{c}{\left[\mathrm{Fe}^{2+}\right] /\left[\mathrm{Fe}^{3+}\right]} \\
\text { ratio }\end{array}$} \\
\hline & & & & $\Sigma \mathrm{Fe}$ & $\Sigma \mathrm{Sn}$ & \\
\hline A & 1.075 & $1 \cdot 591$ & $0 \cdot 817$ & 0.875 & $0 \cdot 000$ & $0 \cdot 089$ \\
\hline B & $1 \cdot 875$ & $1 \cdot 323$ & $0 \cdot 801$ & $0 \cdot 875$ & $0 \cdot 394$ & $0 \cdot 190$ \\
\hline $\mathrm{C}$ & $2 \cdot 113$ & 1.270 & 0.803 & 0.875 & 0.788 & $0 \cdot 220$ \\
\hline D & 2.538 & 1.592 & 0.754 & 0.875 & $1 \cdot 182$ & 0.220 \\
\hline E & $2 \cdot 100$ & $1 \cdot 247$ & 0.930 & 0.875 & 1.576 & 0.226 \\
\hline
\end{tabular}

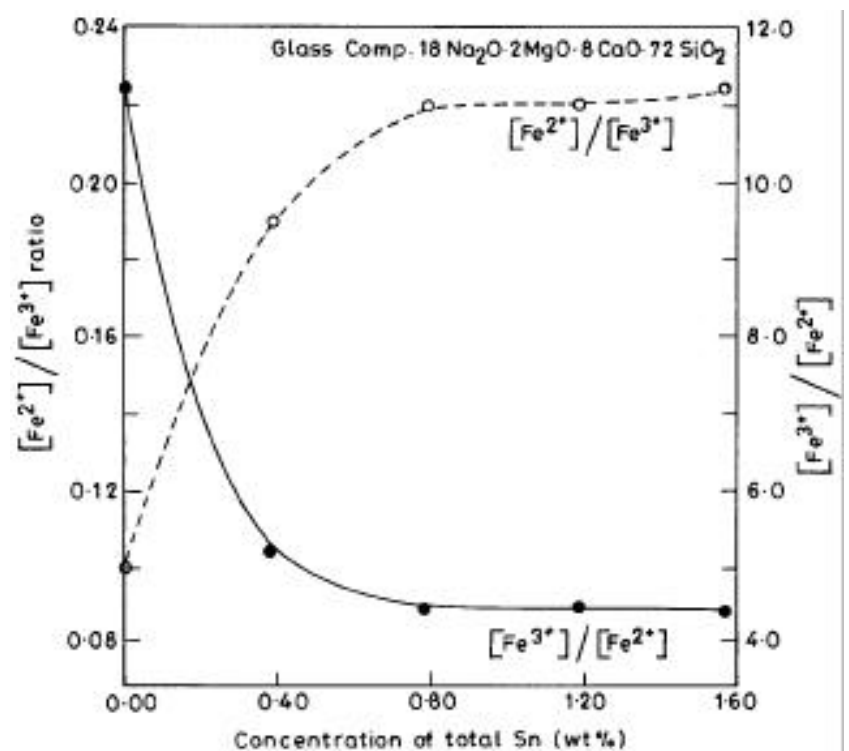

Figure 2. Variation of $\mathrm{Fe}^{2+} / \mathrm{Fe}^{3+}$ ratio and vice versa with concentration of tin in a soda-magnesia-lime-silica glass.

However, there was a little loss of total iron concentration due to its volatilization at this temperature beyond $22 \mathrm{~h}$ with an increase in the proportion of $\mathrm{Fe}^{3+}$ ion with increasing time which was attributed to the loss of iron in ferric state from the glass melt. Further, they observed by chemical analysis of $\mathrm{Fe}^{2+}$ and $\mathrm{Fe}^{3+}$ ions that loss did not disturb the $\mathrm{Fe}^{2+}-\mathrm{Fe}^{3+}$ equilibrium in the silicate glass. The observations recorded for $\mathrm{Mn}^{2+}-\mathrm{Mn}^{3+}$ redox equilibrium did not show any loss of total manganese at high temperature in the molten glass. Johnston (1964) reported some loss of total iron from the melt at high temperature as attributed in form of ferric iron with increasing heat treatment time at $20 \mathrm{~h}$ without affecting the $\mathrm{Fe}^{2+}-\mathrm{Fe}^{3+}$ equilibrium in a sodium disilicate glass. Pyare and Nath (1982) did not mark any loss of total tin also from their alkali silicate melts during $\mathrm{Sn}^{2+}-\mathrm{Sn}^{4+}$ redox equilibrium at $1400^{\circ} \mathrm{C}$ in air atmosphere. Further, the $\mathrm{Sn}^{2+}$ and $\mathrm{Sn}^{4+}$ ions do not produce any colour in the glass.

Cable and Xiang (1989) developed an useful model for the molar extinction coefficient of $\mathrm{Cu}^{2+}$ ion in a sodalime-silica glass which involved the slopes of three di- fferent straight lines plotted for the absorbance maxima/cm for $\mathrm{Cu}^{2+}$ against the total copper concentration for $\mathrm{Cu}^{+}-$ $\mathrm{Cu}^{2+}$ redox equilibrium investigated at three different temperatures. They found that the $\left[\mathrm{Cu}^{+}\right] /\left[\mathrm{Cu}^{2+}\right]$ equilibrium ratio was independent of total copper concentration in the range $0 \cdot 1-1.2 \mathrm{~mol} \% \mathrm{CuO}$. The use of optical absorption for establishing $\mathrm{Cu}^{+}-\mathrm{Cu}^{2+}$ (Cable and Xiang 1989) and $\mathrm{Mn}^{2+}-\mathrm{Mn}^{3+}$ as well as $\mathrm{Fe}^{2+}-\mathrm{Fe}^{3+}$ (Singh and Kumar 1992) redox equilibria by plotting absorbance/cm with time at high temperature for $\mathrm{Cu}^{2+}, \mathrm{Mn}^{3+}$ as well as $\mathrm{Fe}^{2+}$ and $\mathrm{Fe}^{3+}$ ions at their $\lambda_{\max }$ in silicate glasses is quite satisfactory and leading. The equilibrium constant, $K^{\prime}\left[K^{\prime}=\right.$ $\left.\left[\mathrm{Fe}^{3+}\right] /\left[\mathrm{Fe}^{2+}\right]\left[p \mathrm{O}_{2}\right]^{1 / 2}\right]$, calculated from the data of Baak and Hornyak (1961) had been found to be constant at a fixed temperature of $1000^{\circ} \mathrm{C}$ for varying concentrations of total iron from $0 \cdot 102-4.91 \%$ by weight of $\mathrm{Fe}_{2} \mathrm{O}_{3}$ in a silicate glass in air as furnace atmosphere. The value of equilibrium constant was constant at a particular temperature for other temperatures also such as 900, 1100 and $1200^{\circ} \mathrm{C}$ within this concentration range of iron in the glass. Hence, the equilibrium constant, $K^{\prime}$, is independent of total iron concentration irrespective of the rate of approach of $\mathrm{Fe}^{2+}-\mathrm{Fe}^{3+}$ equilibrium in the glass at a constant temperature in air as furnace atmosphere.

The nature and intensity of the colour produced by $3 \mathrm{~d}$ transition metal ion depend not only on the concentration of the colorant but also on the ratio of the oxidized to reduced $[\mathrm{Ox}] /[\mathrm{Red}]$ state of the ions in the glass. The spectrum of iron in the presence of tin in glasses has been presented with reference to that of iron without tin in figure 1 which shows the absorbance/cm vs wavelength curves only for $\mathrm{Fe}^{2+}$ and $\mathrm{Fe}^{3+}$ ions in the glass. The remaining two additional weak bands in the visible region at around $422 \mathrm{~nm}$ and $445 \mathrm{~nm}$ are also due to $\mathrm{Fe}^{3+}$ ion in the silicate glass. There are no bands due to any impurity in the glass other than ferrous and ferric iron contained in the present glass. In the light of earlier interpretations the use of normalized absorbance values for determination of $\left[\mathrm{Fe}^{2+}\right] /\left[\mathrm{Fe}^{3+}\right]$ ratio by Bamford (1977) (equation (1)) is an accurate and reliable one. The optical determination of $\left[\mathrm{Fe}^{2+}\right] /\left[\mathrm{Fe}^{3+}\right]$ ratio is quite independent of total iron concentration as $\Sigma \mathrm{Fe}=\left[\mathrm{Fe}^{2+}\right]+\left[\mathrm{Fe}^{3+}\right]$ in the glass. Further, Singh and Kumar (1992) also found that the ferrous/ferric 
ratio determined by (1) optically in a sodium silicate glass was in good agreement with that of spectrocolorimetric chemical method using ortho-phenanthrolene as a colorimetric reagent. The normalized values of absorbance for the concentrations of the $\mathrm{Fe}^{2+}$ and $\mathrm{Fe}^{3+}$ ion/cm at their $\lambda_{\max }$ thus represent the proportionate concentrations of the iron ions, respectively in the glass as presented in figure 1 and table 1 .

In figure 1, curve (A) represents the optical absorption spectra of soda-magnesia-lime-silica glass containing ions of iron in the optical range 300-1200 $\mathrm{nm}$ in absence of tin. The curves (B), (C), (D) and (E) represent the absorption spectra of $\mathrm{Fe}^{2+}$ and $\mathrm{Fe}^{3+}$ ions in glass melted with an increasing concentration of tin. The increase in absorbance/cm of the glass due to $\mathrm{Fe}^{2+}$ ion at around $1055 \mathrm{~nm}$ in NIR followed by a decrease in absorbance/cm due to $\mathrm{Fe}^{3+}$ in the glass at around $380 \mathrm{~nm}$ in near visible as well as visible region can be explained in terms of role of divalent tin as a thermo reducing agent for $\mathrm{Fe}^{3+}$ ion in the glass. The mechanism of thermo reduction of ferric iron which results in an increase in the higher proportion of ferrous iron can be given by the iron-tin redox interaction at high temperature as per the following reaction

$$
\mathrm{Sn}^{2+}+2 \mathrm{Fe}^{3+} \leftrightarrow \mathrm{Sn}^{4+}+2 \mathrm{Fe}^{2+}
$$

Whenever a polyvalent element is introduced in the molten glass it normally distributes into two valency states viz. an oxidized state and a reduced state. So is the case of iron and tin, when present in the glass they distribute as $\mathrm{Sn}^{2+} / \mathrm{Sn}^{4+}$ and $\mathrm{Fe}^{2+} / \mathrm{Fe}^{3+}$ redox species.

On addition of tin with $0.394-0.788 \%$ in glass sample numbers (B) and (C) the proportion of iron present in $\mathrm{Fe}^{2+}$ state increased substantially followed by a decrease in concentration of ferric iron which is evident from the increase in absorbance/cm of the glass due to $\mathrm{Fe}^{2+}$ ion and vice versa followed by a decrease in intensity of $\mathrm{Fe}^{3+}$ ion in the glass. Since in the glass melt containing oxides of tin and iron, the $\mathrm{Sn}^{2+}, \mathrm{Sn}^{4+}, \mathrm{Fe}^{2+}$ and $\mathrm{Fe}^{3+}$ ions are present at high temperature, as such an increase in total concentration of tin would create a reducing condition in the glass melt due to formation of divalent tin which reduces continuously the concentration of $\mathrm{Fe}^{3+}$ ion in the glass. Hence the proportion of iron present in its ferric state becomes lower and the concentration of $\mathrm{Fe}^{2+}$ ion correspondingly increases respectively (figure 1, table 1). Further addition of tin up to $1.182 \mathrm{wt} \%$ in the glass containing constant iron concentration has also shown a similar effect for an increase in absorbance/cm due to ferrous iron in the glass but the same was not marked up to that extent in case of $\mathrm{Fe}^{3+}$ ion as its absorbance/cm at $\lambda_{\max }$ did not decrease accordingly as shown by curve (D) in figure 1 . At this stage it may be probably due to weaker intensity of ferric iron in comparison to stronger intensity of ferrous iron in the glass at its wavelength maxima. The molar extinction coefficient of $\mathrm{Fe}^{2+}$ ion at its $\lambda_{\max }$ in NIR region $1000-1100 \mathrm{~nm}\left(\Sigma \mathrm{Fe}^{2+}=27.00 \mathrm{~g} \mathrm{~mol} / \mathrm{l} / \mathrm{cm}\right)$, has been ear- lier reported to be around fifty times greater than that of $\mathrm{Fe}^{3+}$ ion $\left(\Sigma \mathrm{Fe}^{3+}=0.5 \mathrm{~g} \mathrm{~mol} / \mathrm{l} / \mathrm{cm}\right)$ at its wavelength maxima in visible region in soda-lime-silica and soda-silica glasses (Bates 1962; Steele 1966). This is the reason behind the stronger absorption by $\mathrm{Fe}^{2+}$ ion in the glass. The addition of still higher amount of tin up to $1.576 \mathrm{wt} \%$ in the glass with the same concentration of iron could not yield any regular effect either for an increase in intensity of $\mathrm{Fe}^{2+}$ ion or decrease in intensity of $\mathrm{Fe}^{3+}$ ion in the glass as shown by curve (E) in figure 1 . This might be attributed to the super saturation of molten glass with tin at $1400^{\circ} \mathrm{C}$ in air atmosphere.

The redox reactions in glasses are diffusion control processes and they take place very slowly due to viscous nature of the glass melt (Nath and Douglas 1965; Paul and Douglas 1965; Singh et al 1978; Cable and Xiang 1989). As the redox potential of $\mathrm{Sn}^{2+}-\mathrm{Sn}^{4+}$ redox pair is lower than that of the redox potential of $\mathrm{Fe}^{2+}-\mathrm{Fe}^{3+}$, the $\mathrm{Sn}^{2+}$ would go on reducing $\mathrm{Fe}^{3+}$ ions to $\mathrm{Fe}^{2+}$ state and convert itself to $\mathrm{Sn}^{4+}$ state according to above redox reaction (2). It is evident from the increase in ferrous/ferric ratio and decrease in ferric/ferrous ratio with the change in concentration of total tin in the present glass according to (1) that the $\mathrm{Sn}^{2+}$ would go on reducing the ferric ions as long as any $\mathrm{Fe}^{3+}$ ion exists in the glass but further occurrence of the mutual redox reaction is stopped by cooling the melt to room temperature frozen in condition. Therefore, some of the tin in divalent state and some of the iron in $\mathrm{Fe}^{3+}\left(3 d^{5}\right)$ state are left in the glass at the end. On cooling the glass from $1400^{\circ} \mathrm{C}$ to room temperature in air atmosphere, the balance of $\mathrm{Sn}^{2+}-\mathrm{Sn}^{4+}$ redox tends to shift more towards $\mathrm{Sn}^{4+}$ state (Pyare and Nath 1982). On account of this tendency, the lower reduction potential of the $\mathrm{Sn}^{2+}$ ion donates two electrons to the neighbouring two $\mathrm{Fe}^{3+}$ ion and is converted to $\mathrm{Sn}^{4+}$ state thereby reducing $\mathrm{Fe}^{3+}$ ions to $\mathrm{Fe}^{2+}$ state as per redox reaction (2) in the glass. Thus the $\mathrm{Sn}^{2+}$ acts as electron donor in the glass and plays the role of reducing agent for ferric ion to achieve higher proportion of ferrous iron essentially required for producing heat absorbing commercial silicate glasses. It may be mentioned here that with the addition of total tin in the glass for a definite concentration of $0.875 \mathrm{wt} \%$ total iron be restricted up to a suitable amount of $0.788 \mathrm{wt} \%$ tin for achieving higher proportion of ferrous for maximum heat absorption. Although, further beyond this, the addition of tin up to $1.182 \mathrm{wt} \%$ has shown the attainment of a maxima in ferrous iron absorbance/cm but the ratio of $\mathrm{Fe}^{2+} / \mathrm{Fe}^{3+}$ or vice versa did not show any change in the glass (table 1, figure 2). The sharp drop of the curve from the maxima on adding $1.576 \%$ tin in glass seems to be futile which is also justified with results present in figures 1 and 2 as well as in table 1 . Therefore, suitable limit of $\Sigma \mathrm{Sn}$ is $0.788 \leq x \leq 1.182 \%$ by wt. for $0.875 \%$ of total iron for maximum absorption of near infrared radiation in the range $1000-1100 \mathrm{~nm}$ in the glass. 


\section{Conclusions}

The role of divalent tin as a thermo reducing agent for ferric to ferrous iron within a limit for making heat absorbing commercial silicate glasses is very significant and useful. The mechanism of process can be given by $\mathrm{Sn}^{2+}$ $\mathrm{Sn}^{4+}$ and $\mathrm{Fe}^{2+}-\mathrm{Fe}^{3+}$ mutual redox interaction in the glass at high temperature. Since $\mathrm{Sn}^{2+}$ and $\mathrm{Sn}^{4+}$ ions do not produce any colour in glasses, the optical method is a reliable and comfortable technique for studying the effect of concentration of tin on $\left[\mathrm{Fe}^{2+}\right] /\left[\mathrm{Fe}^{3+}\right]$ ratio at high temperature in the glass.

\section{Acknowledgements}

The authors gratefully thank the Head, Department of Ceramic Engineering and the Director, Institute of Technology, for providing the necessary facilities for the present work.

\section{References}

Baak T and Hornyak E J 1961 J. Am. Ceram. Soc. 44541 Bamford C R 1961 Phys. Chem. Glasses 2163
Bamford C R 1962 Phys. Chem. Glasses 3189

Bamford C R 1977 in Glass science and technology (New York: Elsevier) 2 p. 35

Bates T 1962 Modern aspects of vitreous state (ed.) J D Mackenzie (London: Butterworths) 2 p. 235

Cable M and Xiang Z D 1989 Phys. Chem. Glasses 30237

Johnston W D 1964 J. Am. Ceram. Soc. 47198

Kumar A, Singh S P and Pyare R 1991 Glastech. Ber. 64106

Majumdar R and Lahiri D 1975 J. Am. Ceram. Soc. 5899

Nath P and Douglas R W 1965 Phys. Chem. Glasses 6197

Paul A and Douglas R W 1965 Phys. Chem. Glasses 6207

Pyare R and Nath P 1982 J. Am. Ceram. Soc. 65549

Russel C, Kohl R and Schaeffer H A 1988 Glastech. Ber. 61209

Shand E B (ed.) 1958 Glass engineering handbook (NewYork: Mcgraw-Hill) 2 p. 210

Singh S P, Prasad G and Nath P 1978 J. Am. Ceram. Soc. 61377

Singh S P and Kumar A 1992 Phys. Chem. Glasses 3361

Steele F N 1966 Absorption of iron in glasses, Ph.D. thesis, University of Sheffield, UK

Stookey S D 1949 J. Am. Ceram. Soc. 32246

Vogel A I (ed.) 1978 A text book of quantitative inorganic analysis (London: Longmans) 4 p. 51

Weyl W A 1951 Coloured glasses (Sheffield, UK: Society of Glass Technology) p. 344

Wong J and Angell C A 1976 Glass structure by spectroscopy (New York: Marcel Dekker) p. 264 